\title{
Effect of S. mutans combinations with bifidobacteria/lactobacilli on biofilm and enamel demineralization
}

\section{Vanessa Rodrigues dos SANTOS(a) Remberto Marcelo Argandoña VALDEZ(a)}

Marcelle DANELON(a) (D)

José Antonio Santos SOUZA(a)

Karina Sampaio CAIAFFA(a)

Alberto Carlos Botazzo DELBEM(a) Cristiane DUQUE(a)

(a) Universidade Estadual Paulista - Unesp, School of Dentistry, Department of Preventive and Restorative Dentistry, Araçatuba, SP, Brazil.
Declaration of Interests: The authors certify that they have no commercial or associative interest that represents a conflict of interest in connection with the manuscript.

\section{Corresponding Author:}

Cristiane Duque

E-mail: cristianeduque@yahoo.com.br

Submitted: June 5, 2020

Accepted for publication: October 30, 2020

Last revision: November 30, 2020
Abstract: The present study evaluated the ability of Bifidobacterium and Lactobacillus species associated with streptococci to increase insoluble extracellular polysaccharide (EPS) production and initial caries lesion progression. Bovine enamel blocks $(\mathrm{n}=190 ; 4 \mathrm{~mm} \times 4 \mathrm{~mm})$ were prepared, selected according to initial surface hardness $(\mathrm{SH})$, and divided into two groups: a) double combinations: S. mutans with Bifidobacterium or Lactobacillus, and b) triple combinations: S. mutans and S. sobrinus with Bifidobacterium or Lactobacillus species. The blocks were exposed to the bacterial associations for 7 days. Subsequently, quantity of EPS from biofilms and caries lesion depth were determined by means of colorimetric and cross-sectional enamel hardness $(\triangle \mathrm{KHN})$ analysis. The data were submitted to one-way analysis of variance, followed by the Bonferroni test $(p<0.05)$. S. mutans with B. animalis or $B$. dentium produced a higher quantity of EPS; $S$. mutans $+B$. animalis led to the highest $\triangle K H N$. S. mutans + S. sobrinus $+B$. longum induced greater EPS and $\triangle \mathrm{KHN}$ values. In conclusion, associations of $B$. animalis and B. longum with streptococci promoted EPS production and caries lesion progression.

Keywords: Bifidobacterium; Lactobacillus; Streptococcus; Polysaccharides; Dental Caries.

\section{Introduction}

Frequent dietary carbohydrate intake can cause dysbiosis of the microbial community, triggered by the overproduction of acids by bacteria. This excessive acid load causes demineralization of the hard tissues of the tooth and development of dental caries. ${ }^{1,2}$ Mutans streptococci, especially Streptococcus mutans, are still considered the most cariogenic bacterial group. ${ }^{3}$ However, other acidogenic and acid-tolerant species may be involved in the onset and progression of caries lesions. ${ }^{2,4}$ Species of the genus Bifidobacterium, also known as bifidobacteria, have received much attention, owing to their beneficial role in human health, including increased adaptive immune response, treatment or prevention of respiratory and urogenital tract infections, and prevention of allergies and atopic diseases in childhood, which is why they are included in food products. ${ }^{5}$ However, studies have detected Lactobacillus and Bifidobacterium in biofilms of white spot lesions and dentin caries. ${ }^{6}$ In a prior study, B. animalis and 
B. longum were the most acidogenic and aciduric strains, comparable to caries-associated bacteria, such as S. mutans and L. casei. ${ }^{7}$

S. mutans is able to produce enzymes called glucosyltransferases, which hydrolyze sucrose from the diet into glucose and fructose. Glucose residues bind to each other to form extracellular polysaccharides (EPS) or insoluble glucans, responsible for adhesion of microorganisms to dental surfaces, and formation of the extracellular matrix that structures the dental biofilm. Biofilm formation results from sugar degradation and so-called microbial coaggregation, a process whereby genetically distinct microorganisms specifically recognize and become attached to one another. This interaction promotes organizational and cell-cell interactions that increase the resistance of the species individually, and the biofilm as a whole. ${ }^{8}$ A previous study found a significant increase in biofilm formation and enamel demineralization when S. mutans were combined with $B$. animalis and B. longum. ${ }^{7}$ Thus, this study proposed researching a sequence to this earlier study, involving the ability of some species of Bifidobacterium and Lactobacillus to combine with streptococci, and ultimately increase insoluble EPS production, leading to initial caries lesion progression.

\section{Methodology}

\section{Bacterial strains and growth conditions}

The bacterial species evaluated in this study were B. animalis (from ACTIVIA ${ }^{\circledR}$ ), B. longum, (ATCC 15707), B. lactis (LMG 18905), and B. dentium (ATCC 27678); L. acidophilus (ATCC 4356), L. casei (ATCC 393); S. mutans (ATCC 25175 and 3VF2), and S. sobrinus (ATCC 27607). All ATCC strains were obtained from the Oswaldo Cruz Foundation (FIOCRUZ, Rio de Janeiro, RJ, Brazil), and the André Tosello Foundation (Campinas, SP, Brazil). S. mutans $3 \mathrm{VF} 2$ is a highly acidogenic clinical strain that was previously characterized and also provided by Dr. Renata de Oliveira Mattos-Graner (FOP-UNICAMP, Piracicaba, Brazil). ${ }^{9}$ B. animalis was isolated from ACTIVIA $^{\circledR}$ yogurt. Bifidobacterium, Lactobacillus, and Streptococcus species were isolated from the following media: transgalactosylated oligosaccharides propionate agar supplemented with lithium mupirocin (50 mg/L) (TOS-MUP agar; Merck Millipore, Darmstadt, Germany), Rogosa Agar (Difco Laboratories, Detroit, USA) and Mitis Salivarius Agar (MSA, Difco), respectively.7 All bacteria were grown at $37^{\circ} \mathrm{C}$ for $48 \mathrm{~h}$ in a $5 \% \mathrm{CO}_{2}$ atmosphere.

\section{Experimental design}

After approval of the Ethics Committee of the Araçatuba Dental School-UNESP (number: 197/2013), enamel blocks $(4 \mathrm{~mm} \times 4 \mathrm{~mm}, \mathrm{n}=190)$ were obtained from bovine incisors, and kept in $2 \%$ formalin, $\mathrm{pH} 7.0$, for 30 days. ${ }^{10}$ The enamel surface of the blocks was polished, after which the initial surface hardness (SHi) was measured using a 5114 MicroMet microhardness tester (Buehler, Lake Bluff, IL, USA) with a Knoop-type indenter, and with a static load of $25 \mathrm{~g}$ for $10 \mathrm{~s}$. Five indentations $100 \mu \mathrm{m}$ apart were made in the central region of each block. The experimental design was randomized, and the blocks were divided into two or three bacterial combinations: Group $1(n=90)$ : combinations with Streptococcus mutans (3FV2) totaling 9 combinations; Group $2(\mathrm{n}=80)$ : combinations with S. mutans + S. sobrinus totaling 8 combinations. Each group had $S$. mutans $(\mathrm{n}=10)$ and $S$. mutans $+S$. sobrinus controls $(n=10)$, which were also analyzed.

\section{In vitro initial caries lesion induction and enamel hardness analysis}

The induction of artificial caries was modeled after the study by Lima et al.,11 and modified by Valdez et al. ${ }^{7}$ The bovine enamel blocks were completely isolated with a thin layer of nail varnish, except for the external surface (area $=16 \mathrm{~mm}^{2}$ ), and placed individually into a modified artificial caries solution (brain heart infusion supplemented with $1 \%$ yeast extract, $0.5 \%$ glucose, $1 \%$ sucrose, and $2 \%$ of the bacterial culture $-10^{8}$ cells $/ \mathrm{mL}$ ) for 7 days at $37^{\circ} \mathrm{C}$. The culture medium was changed every $48 \mathrm{~h}$. Bacterial viability was checked during the experiment after the dilution of random wells, and the plating of each type of bacteria in specific media (TOS-MUP agar for bifidobacteria, Rogosa Agar for lactobacilli, and MSA for streptococci). ${ }^{7}$ Afterwards, 14 indentations were made in the enamel, at different distances $-5,10,15,20,25,30,40,50,70,90,110,130,220$, and $330 \mu \mathrm{m}-$ and different depths from the surface, in the central region. The indentations were spaced 
$100 \mu \mathrm{m}$ from each other, as measured with a Micromet 5114 hardness tester (Buehler, Lake Bluff, USA) and the Buehler OmniMet software program (Buehler), and were made with a Knoop diamond indenter under a 5-g load for $10 \mathrm{~s}$. The averages were calculated for each distance. The integrated hardness (KHN x $\mu \mathrm{m})$ of the lesion was calculated by the trapezoidal rule (GraphPad Prism, version 3.02) and subtracted from the integrated hardness for sound enamel, to obtain the integrated area of the subsurface regions in the enamel. This integrated area was named subsurface enamel hardness $(\Delta \mathrm{KHN} ; \mathrm{KHN} \times \mu \mathrm{m}){ }^{10}$

\section{Insoluble extracellular polysaccharide (EPS) analysis}

After 7 days, the biofilm that formed on the enamel blocks was collected and analyzed. ${ }^{12,13}$ Carbohydrate analysis was performed using the phenol-sulfuric acid procedure, ${ }^{14}$ and the results were expressed in $\mu \mathrm{g} / \mathrm{g}$ EPS (dry weight).

\section{Statistical analysis}

Statistical analysis was performed using the SPSS program version 17.1, considering $p<0.05$ as significant. The data for DKHN and EPS were found to be normal (Shapiro-Wilk) and have homogeneous (Bartlett) distribution, and were analyzed using one-way analysis of variance (ANOVA), followed by the Bonferroni test.

\section{Results}

When S. mutans was inoculated with L. casei shirota and B. longum, $\triangle \mathrm{KHN}$ was similar to $S$. mutans inoculated alone. In the other groups, there was a greater loss of hardness compared with the control group $(\mathrm{p}<0.05)$. The double combination that induced the highest loss of subsurface hardness was $S$. mutans $+B$. animalis (Table 1). The $S$. mutans $+S$. sobrinus + $B$. longum group induced a greater loss of subsurface hardness compared with the S. mutans $+S$. sobrinus group, and the highest quantity of EPS compared to the other groups $(\mathrm{p}<0.05)$ (Table 2$)$.

\section{Discussion}

In the present study, the association of the same species of Bifidobacteria, B. animalis and B. longum with S. mutans or with S. mutans + S. sobrinus, respectively, induced the highest loss of subsurface enamel hardness. Bifidobacterium and Lactobacillus adhere poorly to the dental structure, and require mediation by other oral bacteria. Consequently, they are unable to form biofilm, as formed by cariogenic bacteria. ${ }^{7}$ In line with the aims of the present article, dental enamel demineralization tests were performed with these species, together with S. mutans and/or S. sobrinus. Campos et al. ${ }^{15}$ showed that the associations of S. mutans and L. casei or S. mutans, L. acidophilus and L. casei led to greater loss

Table 1. Mean (standard deviation) of subsurface enamel hardness ( $\triangle K H N$ ) and insoluble extracellular polysaccharides (EPS) measurements for the double combinations.

\begin{tabular}{llc}
\hline Group & $\Delta \mathrm{KHN}(\mathrm{KHN} \times \mu \mathrm{m})$ & EPS $(\mu \mathrm{g} / \mathrm{g})$ \\
\hline S. mutans & $5,025.5(2,401.1)^{\mathrm{A}}$ & $2.6(0.9)^{\mathrm{a}}$ \\
S. mutans + S. sobrinus & $7,794.6(1,202.8)^{\mathrm{B}}$ & $3.1(1.1)^{\mathrm{a}}$ \\
S. mutans + L. casei & $6,690.4(1,953.0)^{\mathrm{B}}$ & $2.8(0.9)^{\mathrm{a}}$ \\
S. mutans + L. casei shirota & $4,984.0(1,508.5)^{\mathrm{A}}$ & $2.3(0.7)^{\mathrm{a}}$ \\
S. mutans + L. acidophilus & $7,079.6(3,321.1)^{\mathrm{B}}$ & $5.5(2.3)^{\mathrm{b}}$ \\
S. mutans + B. dentium & $7,281.7(1,637.4)^{\mathrm{B}}$ & $4.5(1.6)^{\mathrm{b}, \mathrm{c}}$ \\
S. mutans + B. longum & $4,140.3(1,613.3)^{\mathrm{A}}$ & $2.1(0.6)^{\mathrm{a}}$ \\
S. mutans + B. animalis & $9,186.9(1,859.7)^{\mathrm{C}}$ & $3.9(1.6)^{\mathrm{c}}$ \\
S. mutans + B. lactis & $7,096.9(2,970.0)^{\mathrm{B}}$ & $2.7(0.7)^{\mathrm{a}}$ \\
\hline
\end{tabular}

ADifferent uppercase letters show statistical difference among the groups, according to the ANOVA and Bonferroni tests; ${ }^{\circ}$ Different lowercase letters show statistical difference among the groups according to the ANOVA and Bonferroni tests. 
Table 2. Mean (standard deviation) subsurface enamel hardness $(\triangle K H N)$ and insoluble extracellular polysaccharide (EPS) measurements for triple combinations.

\begin{tabular}{lcc}
\hline Group & $\Delta K H N(K H N \times \mu m)$ & $E P S(\mu \mathrm{g} / \mathrm{g})$ \\
\hline S. $m+$ S. sobrinus & $7,794.6(1,202.8)^{\mathrm{A}}$ & $3.1(1.1)^{\mathrm{a}}$ \\
S. $m+$ S. $s+$ L. casei & $5,862.8(3,850.3)^{\mathrm{B}}$ & $4.7(1.2)^{\mathrm{b}}$ \\
S. $m+$ S. $s+$ L. casei shirota & $6,373.1(2,511.2)^{\mathrm{B}}$ & $5.1(2.2)^{\mathrm{b}}$ \\
S. $m+$ S. $s+$ L. acidophilus & $8,689.6(1,504.7)^{\mathrm{A}}$ & $4.4(1.4)^{\mathrm{b}}$ \\
S. $m+$ S. $s+$ B. dentium & $6,958.2(1,819.4)^{\mathrm{A}}$ & $5.3(3.3)^{\mathrm{b}}$ \\
S. $m+$ S. $s+$ B. longum & $10,022.3(2,487.9)^{\mathrm{C}}$ & $6.1(2.3)^{\mathrm{c}}$ \\
S. $m+$ S. $s+$ B. animalis & $8,040.5(3,516.3)^{\mathrm{A}}$ & $5.2(0.8)^{\mathrm{b}}$ \\
S. $m+$ S. $s+$ B. lactis & $5,563.9(3,011.2)^{\mathrm{B}}$ & $3.2(1.7)^{\mathrm{a}}$ \\
\hline
\end{tabular}

${ }^{A}$ Different uppercase letters show statistical difference among the groups, according to ANOVA and Bonferroni tests; ${ }^{\circ}$ Different lowercase letters show statistical difference among the groups, according to ANOVA and Bonferroni tests

of enamel surface hardness and higher depth values of carious lesions, observed in the first four days of induction, and lesions similar to erosion after 20 days of cariogenic challenge, thus corroborating the results obtained in the present study.

Among the species of Bifidobacteria evaluated in this study, only $B$. dentium was isolated in the oral cavity. B. dentium led to the loss of enamel subsurface hardness when associated with $S$. mutans and with both S. mutans and S. sobrinus. In a previous study performed by this research group, the association of $B$. dentium with species of streptococci did not produce greater surface loss compared with streptococci evaluated alone. ${ }^{7}$ In addition, $B$. dentium did not stand out as an acid-producing or acid-resistant strain, in comparison with $S$. mutans and other cariogenic species. ${ }^{7}$

In the present study, EPS was quantified from biofilms developed on the surface of bovine enamel. This is why the combinations of bacterial species followed the same pattern as that observed in the subsurface hardness analysis. Therefore, the species of bifidobacteria were evaluated only in combination with S. mutans and S. mutans + S. sobrinus. Although bifidobacteria cannot adhere to enamel, they contribute toward increasing EPS production, and may constitute a substrate for associated cariogenic bacteria. In the present study, B. animalis and B. longum, associated respectively with $S$. mutans or with $S$. mutans + S. sobrinus, produced greater loss of subsurface hardness, and also presented the highest quantity of EPS. This suggests that these species could provide more substrate for cariogenic bacteria, consequently increasing the biofilm biomass.

\section{Conclusion}

The association of $B$. animalis and B. longum with S. mutans or $S$. mutans $+S$. sobrinus promotes the greatest hardness loss and extracellular polysaccharide production.

\section{Acknowledgments}

The authors would like to thank Renata de Oliveira Mattos-Graner (FOP-Unicamp, Brazil), Anne C. R. Tanner and Christine A. Kressirer (Forsyth Institute, Cambridge, USA) for providing the bacterial strains, and Fapesp (\#2014/02072-1) and Capes-Procad (grant \# 88881.068437/2014-01) for their financial support.

\section{References}

1. Giacaman RA. Sugars and beyond. The role of sugars and the other nutrients and their potential impact on caries. Oral Dis. 2018 Oct;24(7):1185-97. https://doi.org/10.1111/odi.12778 
2. Tanner AC, Kressirer CA, Rothmiller S, Johansson I, Chalmers NI. The caries microbiome: implications for reversing dysbiosis. Adv Dent Res. 2018 Feb;29(1):78-85. https://doi.org/10.1177/0022034517736496

3. Banas JA, Drake DR. Are the mutans streptococci still considered relevant to understanding the microbial etiology of dental caries? BMC Oral Health. 2018; 31;18(1):129. https://doi.org/10.1186/s12903-018-0595-2

4. Richards VP, Alvarez AJ, Luce AR, Bedenbaugh M, Mitchell ML, Burne RA, Nascimento MM. Microbiomes of site-specific dental plaques from children with different caries status. Infect Immun. 2017 Jul;85(8):e00106-17. https://doi.org/10.1128/IAI.00106-17

5. Saxelin M, Tynkkynen S, Mattila-Sandholm T, Vos WM. Probiotic and other functional microbes: from markets to mechanisms. Curr Opin Biotechnol. 2005 Apr;16(2):204-11. https://doi.org/10.1016/i.copbio.2005.02.003

6. Ruyven FO, Lingström P, Houte J, Kent R. Relationship among mutans streptococci, "low-pH" bacteria, and lodophilic polysaccharide-producing bacteria in dental plaque and early enamel caries in humans. J Dent Res. 2000 Feb;79(2):778-84. https://doi.org/10.1177/00220345000790021201

7. Valdez RM, Santos VR, Caiaffa KS, Danelon M, Arthur RA, Negrini TC, et al. Comparative in vitro investigation of the cariogenic potential of bifidobacteria. Arch Oral Biol. 2016 Nov;71:97-103. https://doi.org/10.1016/j.archoralbio.2016.07.005

8. Ren Z, Kim D, Paula AJ, Hwang G, Liu Y, Li J, et al. Dual-targeting approach degrades biofilm matrix and enhances bacterial killing. J Dent Res. 2019 Mar;98(3):322-30. https://doi.org/10.1177/0022034518818480

9. Mattos-Graner RO, Napimoga MH, Fukushima K, Duncan MJ, Smith DJ. Comparative analysis of Gtf isozyme production and diversity in isolates of Streptococcus mutans with different biofilm growth phenotypes. J Clin Microbiol. 2004 Oct;42(10):4586-92. https://doi.org/10.1128/JCM.42.10.4586-4592.2004

10. Danelon M, Pessan JP, Souza-Neto FN, de Camargo ER, Delbem AC. Effect of fluoride toothpaste with nano-sized trimetaphosphate on enamel demineralization: an in vitro study. Arch Oral Biol. 2017 Jun;78:82-7. https://doi.org/10.1016/i.archoralbio.2017.02.014

11. Lima LM, Motisuki C, Spolidorio DM, Santos-Pinto L. In vitro evaluation of probiotics microorganisms adhesion to an artificial caries model. Eur J Clin Nutr. 2005 Jul;59(7):884-6. https://doi.org/10.1038/si.ejcn.1602158 PMID:15915155

12. Santos MN, Santos LM, Francisco SB, Cury JA. Relationship among dental plaque composition, daily sugar exposure and caries in the primary dentition. Caries Res. 2002 Sep-Oct;36(5):347-52. https://doi.org/10.1159/000065959

13. Ccahuana-Vásquez RA, Tabchoury CP, Tenuta LM, Del Bel Cury AA, Vale GC, Cury JA. Effect of frequency of sucrose exposure on dental biofilm composition and enamel demineralization in the presence of fluoride. Caries Res. 2007;41(1):9-15. https://doi.org/10.1159/000096100

14. DuBois M, Gilles KA, Hamilton JK, Rebers PA, Smith F. Colorimetric method for determination of sugars and related substances. Anal Chem. 1956;28(3):350-6. https://doi.org/10.1021/ac60111a017.

15. Campos PH, Sanabe ME, Rodrigues JA, Duarte DA, Santos MT, Guaré RO, et al. Different bacterial models for in vitro induction of non-cavitated enamel caries-like lesions: microhardness and polarized light miscroscopy analyses. Microsc Res Tech. 2015 Jun;78(6):444-51. https://doi.org/10.1002/jemt.22493 